\title{
Diagnostic yield of array CGH in patients with autism spectrum disorder in Hong Kong
}

\author{
Wai-Kwan Siu ${ }^{1,2}$, Ching-Wan Lam ${ }^{1 *}$, Chloe Miu Mak ${ }^{2}$, Elizabeth Tak-Kwong Lau ${ }^{3}$, Mary Hoi-Yin Tang ${ }^{3}$, \\ Wing-Fai Tang ${ }^{3}$, Rachel Sui-Man Poon-Mak ${ }^{4}$, Chi-Chiu Lee ${ }^{5}$, Se-Fong Hung ${ }^{5}$, Patrick Wing-Leung Leung ${ }^{6}$, \\ Karen Ling Kwong ${ }^{7}$, Eric Kin-Cheong Yau ${ }^{8}$, Grace Sui-Fun $\mathrm{Ng}^{8}$, Nai-Chung Fong ${ }^{8}$ and Kwok-Yin Chan ${ }^{8}$
}

\begin{abstract}
Background: Chromosomal microarray offers superior sensitivity for identification of submicroscopic copy number variants (CNV) and it is advocated to be the first tier genetic testing for patients with autism spectrum disorder (ASD). In this regard, diagnostic yield of array comparative genomic hybridization (CGH) for ASD patients is determined in a cohort of Chinese patients in Hong Kong.

Methods: A combined adult and paediatric cohort of 68 Chinese ASD patients (41 patients in adult group and 27 patients in paediatric group). The genomic DNA extracted from blood samples were analysed by array CGH using NimbleGen CGX-135K oligonucleotide array.

Results: We identified 15 CNV and eight of them were clinically significant. The overall diagnostic yield was $11.8 \%$. Five clinically significant CNV were detected in the adult group and three were in the paediatric group, providing diagnostic yields of 12.2 and $11.1 \%$ respectively. The most frequently detected CNV was 16p13.11 duplications which were present in 4 patients ( $5.9 \%$ of the cohort).
\end{abstract}

Conclusions: In this study, a satisfactory diagnostic yield of array CGH was demonstrated in a Chinese ASD patient cohort which supported the clinical usefulness of array CGH as the first line testing of ASD in Hong Kong.

Keywords: Autism spectrum disorder, Chinese, ARRAY CGH

\section{Background}

Autism spectrum disorder (ASD) is a collective term describing a range of neurodevelopmental disorders with core features of deficits in communications and social interactions, accompanied by stereotyped behaviours and restricted interest. The global prevalence was reported to be 1 in 161 children, affecting more males than females [1]. Being regarded as a crucial factor for the aetiology of ASD, genetic alterations identified in affected patients are remarkably heterogeneous across the whole genome [2].

Evidently, a number of chromosomal abnormalities have been recognised to be associated with ASD phenotype [3]. Nevertheless, the diagnostic yield of

\footnotetext{
*Correspondence: ching-wanlam@pathology.hku.hk

1 Department of Pathology, The University of Hong Kong, 102 Pokfulam Road, Hong Kong, China

Full list of author information is available at the end of the article
}

conventional G-banded karyotype has been reported to be only $3 \%$ [4]. Notably, chromosomal microarray (CMA) is regarded as a robust and comprehensive tool for genome-wide detection of submicroscopic deletions and duplications, which are named as copy number variants $(\mathrm{CNV})$. The advantage of high resolution using CMA translates into major improvement in the detection rate. Indeed, the implications of rare $\mathrm{CNV}$ on the pathogenesis of ASD have been increasingly acknowledged [5]. CMA is now regarded as the first tier genetic testing for ASD patients [6]. The diagnostic importance of CMA for ASD has been demonstrated in diverse clinical settings [7-9]. Overall, the frequency of finding clinically significant CNV in ASD patients has been shown to be approximately 7-9 \% [10, 11]. Moreover, Tammimies et al. has demonstrated that the diagnostic yield was significantly higher in those with more complex morphological phenotype [12]. Nevertheless, in majority of the CNV studies 
in ASD, the subjects are predominately from Caucasian ancestry. Seemingly, genomic data in other population is crucial, especially when CMA are increasingly adopted in clinical laboratories.

In this study, we determined the clinical usefulness of CMA in evaluation of ASD patients in our population. Array comparative genomic hybridization (CGH) is the platform that used for identification of $\mathrm{CNV}$ in a Chinese ASD patient cohort from Hong Kong. We present here the diagnostic yield of this investigative tool in a combined adult and paediatric cohort.

\section{Methods}

\section{Patients}

We evaluated a combined adult and paediatric cohort of 68 patients ( 60 males and 8 females). All the patients are unrelated. The adult patients were recruited from a cohort of a local study on the adult outcome of children with autism with normal intelligence [13]. Fortyone patients were in the adult group (39 males and 2 females) and the age was 22-33 years (median 27 years). This group consisted of ASD patients who were diagnosed in childhood by psychiatrists, paediatricians or clinical psychologists before year 1990, using the Diagnostic and Statistical Manual of Mental Disorders, Third Revised Edition, and confirmed with the development, dimensional and diagnostic interview [14] during adulthood in the aforementioned study. The adult cohort was also assessed with Wechsler Adult Intelligence ScaleThird Edition (WAIS-III) Chinese version [15] and confirmed to have normal intelligence with full IQ score of 75 or above. They had follow-up in clinic under Kwai Chung Hospital. In the paediatric group, 27 patients were recruited (21 males and 6 females), aged 2-15 (median 5 years). The paediatric patients were assessed in the Department of Paediatrics and Adolescent Medicine of Princess Margaret Hospital or Tuen Mun Hospital. The paediatric patients were assessed using autism diagnostic interview-revised (ADI-R) [16] to confirm the diagnosis of ASD. Thirteen patients in the paediatric group (52.0\%) also had developmental delay. The study was approved by the Clinical Research Ethic Committee of Kowloon West Cluster \& New Territories West Cluster of Hospital Authority (Reference number: KWC/FR/10-007 and NTWC/CREC/1004/11). Informed consent was obtained from all parents or patients.

\section{Array CGH and data interpretation}

Peripheral blood samples were collected in EDTA tubes for genomic DNA extraction using QIAamp Blood Kit (Qiagen, Hilden, Germany). The quantity of DNA in the samples was measured by Nanodrop spectrophotometer and all samples had an $\mathrm{A}_{260} / \mathrm{A}_{280}$ ratio more than or equal to 1.8. Agarose gel electrophoresis was used for the assessment of DNA quality to preclude any degradation or RNA contamination. NimbleGen CGX-135K oligonucleotide arrays [Genome Build: hg18] were used in this study and the method was previously described [17]. This platform had been used in multiple clinical microarray studies [18-21]. The data was analysed using DEVA (Roche NimbleGen, Wisconsin, USA) and Genoglyphix (Signature Genomics, Spokane, USA). The quality of array CGH experiments has been assessed through the parameters in the quality metric report. The reports include "signal range" and "ratio range" which represent the uniformity of $\log -2$ ratio over the array. The lower the value, the better the quality of the data. The array CGH data of all samples had "signal range" and "ratio range" below the cutoffs suggested by the manufacture which were $<1.0$ and $<1.5$ respectively.

The clinical significance of the CNV detected was determined using the information available in the open access databases including Database of Chromosomal Imbalance and Phenotype in Human using Ensembl Resources (DECIPHER), Database of Genomic Variant (DGV), International Standards for Cytogenomic Arrays Consortium Database (ISCA), and Simons Foundation Autism Research Initiative Gene (SFARI Gene). Categorization of $\mathrm{CNV}$ is based on available information on the clinical significance of genes in the region of deletions or duplications via the search in The University of California Santa Cruz (UCSC) Genome Browser, Pubmed and Online Mendelian Inheritance in Man (OMIM). CNV are classified into pathogenic, uncertain clinical significance and benign based on American College of Medical Genetics guideline [22] and the pathogenic and likely pathogenic $\mathrm{CNV}$ are deemed to be clinically significant. Detection rate was defined as the number of patients with $\mathrm{CNV}$ divided by the total number of patients tested and diagnostic yield was determined as the percentage of patients with clinically significant $\mathrm{CNV}$ among patients tested.

\section{Results}

Table 1 shows the summary of the patient characteristics and CNV findings. We identified $15 \mathrm{CNV}$ in the cohort 68 ASD patients, giving CNV detection rate of $22.1 \%$. Among patients with CNV, there were 13 males and two females. The CNV detection rates in male and female patients were 21.7 and $25 \%$ respectively. In the adult group, CNV were detected in 8 male patients. The overall CNV detection rate in the adult group was $19.5 \%$ for all adults and $20.5 \%$ for male adults. Seven patients with $\mathrm{CNV}$ were from the paediatric group with five males and two female. The overall CNV detection rate in the paediatric group was $25.9 \%$ (23.8 \% for male and $33.3 \%$ for female). 
Table 1 Summary of patient characteristics and CNV findings

\begin{tabular}{llll}
\hline & Overall & Adult group & Paediatric group \\
\hline Number of patients & 68 & 41 & 27 \\
Male & 60 & 39 & 21 \\
Female & 8 & 2 & 6 \\
Age range (median) [years] & $2-33(25)$ & $22-33(27)$ & $2-15(5)$ \\
Intelligence quotient & $\mathrm{N} / \mathrm{A}$ & $75-129(96)$ & $\mathrm{N} / \mathrm{A}$ \\
$\quad$ (median) & & & \\
Total number of CNV & 15 & 8 & 7 \\
(Detection rate \%) & $(22.1)$ & $(19.5)$ & $(25.9)$ \\
Detected in male & 13 & 8 & 4 \\
(Detection rate \%) & $(21.7)$ & $(20.5)$ & $(19.0)$ \\
Detected in female & 2 & 0 & 3 \\
(Detection rate \%) & $(25)$ & $(0)$ & $(50)$ \\
Clinical significant CNV & 8 & 5 & 3 \\
(Diagnostic yield \%) & $(11.8)$ & $(12.2)$ & $(11.1)$ \\
Detected in male & 6 & 5 & 1 \\
(Diagnostic yield \%) & $(10)$ & $(12.8)$ & $(4.8)$ \\
Detected in female & 2 & 0 & 2 \\
(Diagnostic yield \%) & $(25)$ & $(0)$ & $(33.3)$ \\
\hline
\end{tabular}

N/A not available

Among the detected CNV, eight of them were classified as clinically significant, which gives an overall diagnostic yield of $11.8 \%$. Five was from the adult group and three was the paediatric group and the diagnostic yield was 12.2 and $11.1 \%$ respectively. All patients with clinically significant $\mathrm{CNV}$ in the adult group were male. In the paediatric group, the clinically significant $\mathrm{CNV}$ were found in one male and two female patients. Variants of uncertain clinical significance (VOUS) were detected in seven patients, which contributed to $10.3 \%$ of the entire cohort. The detected $\mathrm{CNV}$ were compared to the published CNV map of the human genome [23]. The array CGH data was shown in Additional file 1: Figure S1-S12.

The eight clinically significant $\mathrm{CNV}$ contributed to $53.3 \%$ of all CNV (8 out of $15 \mathrm{CNV}$ ) detected. Four of them were deletions and another four are duplications. The largest clinically significant CNV identified sized $14.53 \mathrm{Mb}$ while the smallest was $0.12 \mathrm{Mb}$. Seven of them were below $5 \mathrm{Mb}(87.5 \%)$ which was the size range not routinely detectable by karyotype. The size of five CNV was between 1 and $5 \mathrm{Mb}(62.5 \%)$ and two were $<1 \mathrm{Mb}$ (25.0\%).

The clinically significant CNV were listed in Table 2 . Among the clinically significant $\mathrm{CNV}, 1.16 \mathrm{Mb}$ microduplications within chromosome band 16p13.11 were most frequently observed and these were detected in three adult patients and one paediatric patient. In the adult group, one patient had $1.97 \mathrm{Mb}$ microdeletion at $15 \mathrm{q} 23-\mathrm{q} 24.1$ encompassing 19 genes. Another had $0.26 \mathrm{Mb}$ microdeletion within chromosome band 15q11.2 overlapping Prader-Willi/Angelman region and involving NIPA1 gene. In the paediatric group, one patient had a large terminal deletion of chromosome 18 from band q22.1 to q23 which is $14.53 \mathrm{Mb}$ in size. Another paediatric patient had 14q22.1 microdeletion involving the whole NIN gene.

For the seven VOUS, six were duplications and one was deletion. All of them were less than $5 \mathrm{Mb}$. The size of VOUS ranged from 0.08 to $0.97 \mathrm{Mb}$. The VOUS are listed in Table 3.

\section{Discussion}

We identified $11.8 \%$ patients with clinically significant $\mathrm{CNV}$ in our ASD cohort by array CGH. The diagnostic yield in this study was in keeping with other studies [11, 24]. If conventional G-banded karyotype was used as the first line test, only one patient in our cohort $(1.5 \%)$ would have chromosomal abnormality detected microscopically. With high resolution, array CGH is capable of identifying the underlying chromosomal cause of ASD in a much greater number of patients. Evidently, our results demonstrated a satisfactory diagnostic yield of array CGH for genetic diagnosis in ASD patients, confirming its clinical usefulness as first tier testing. The diagnostic yield of the in the adult and paediatric group was comparable.

In addition, array CGH also allowed better delineation of the breakpoints of the CNV. The improved accuracy facilitated genotype-phenotype correlation and identification of candidate genes [6]. In the patient with 15q11.2 deletion at Prader-Willi/Angelman region, the deletion overlapped with reported microdeletion at $15 \mathrm{q} 11.2$ between breakpoint (BP) 1 to 2 which was a susceptibility region for autism and language delay $[25,26]$. The phenotype of this BP1-BP2 microdeletion is different from those with deletions with proximal breakpoint at BP1 or BP2 and distal breakpoint at BP3 which result in classical Prader-Willi/Angelman syndrome. In the patient with deletion at 15q23-q24.1, the deletion overlapped with previously reported $15 \mathrm{q} 24$ deletion in ASD patients [27, 28]. The improved breakpoint delineation drove the identification of novel disease gene NEO1 which conferred aetiological importance in ASD [29].

The largest CNV detected in this cohort was a deletion within chromosome band 18q21.1q23. The deletion, arr 18q22.1q23 $(61,576,686-76,114,624) \times 1$, encompassed a minimum size of $14.53 \mathrm{Mb}$ and involved 38 genes from $C D H 7$ to PARD6G (Additional file 1: Figure S13). Deletions of $18 \mathrm{q}$ were deemed to be a particularly heterogeneous genomic disorder as no recurrent breakpoints were identified [30]. With remarkable genomic heterogeneity, the phenotypes of patients with $18 \mathrm{q}$ deletion 


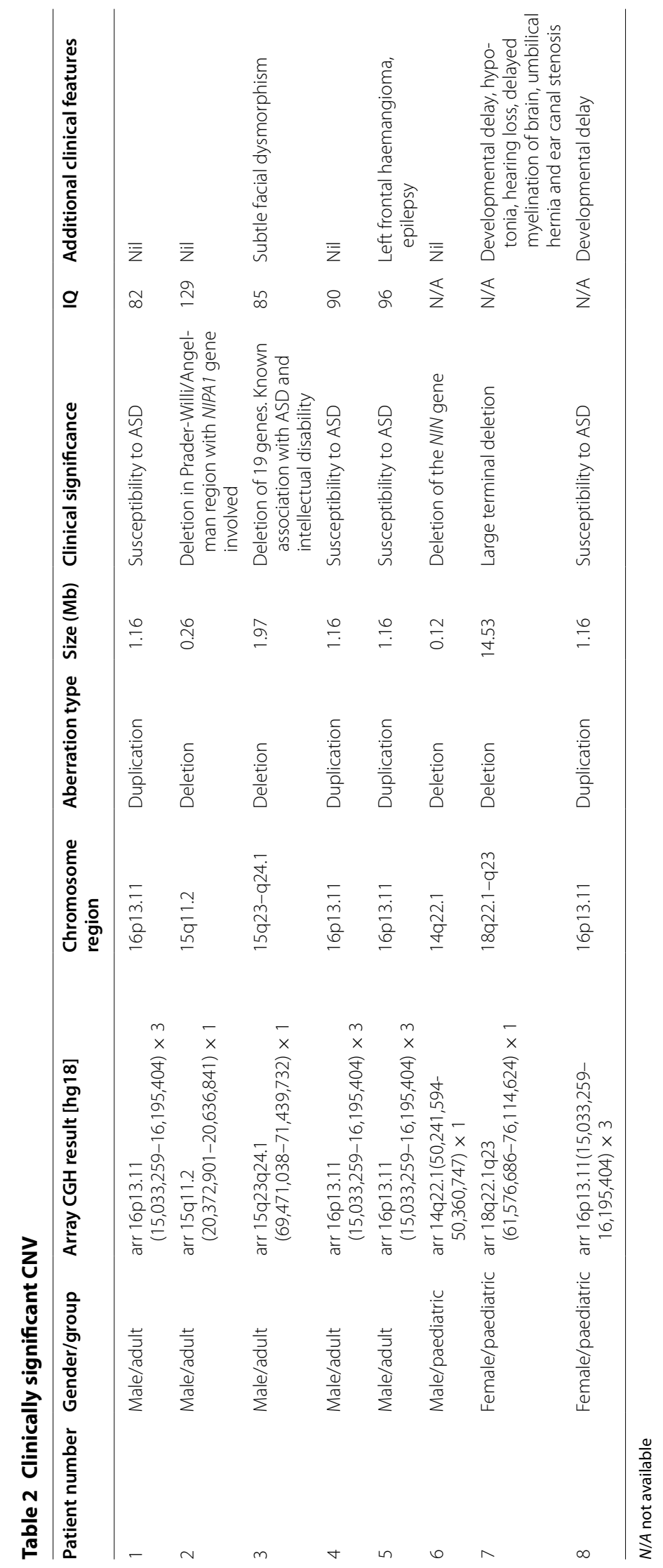


Table 3 List of variants of uncertain significance

\begin{tabular}{|c|c|c|c|c|c|c|c|}
\hline $\begin{array}{l}\text { Patient } \\
\text { number }\end{array}$ & Gender/group & Array CGH result [hg18] & $\begin{array}{l}\text { Chromosome } \\
\text { region }\end{array}$ & $\begin{array}{l}\text { Aberration } \\
\text { type }\end{array}$ & $\begin{array}{l}\text { Size } \\
(\mathrm{Mb})\end{array}$ & IQ & $\begin{array}{l}\text { Additional } \\
\text { clinical features }\end{array}$ \\
\hline 9 & Male/adult & arr 3q13.3 $(111,747,166-112,297,084) \times 3$ & $3 q 13.3$ & Duplication & 0.55 & 96 & Nil \\
\hline 10 & Male/adult & arr 1q44 $(244,474,644-245,087,421) \times 3$ & $1 q 44$ & Duplication & 0.61 & 85 & $\mathrm{Nil}$ \\
\hline 11 & Female/adult & arr 11q24.1 $(122,330,312-122,406,276) \times 3$ & $11 q 24.1$ & Duplication & 0.08 & 103 & Nil \\
\hline 12 & $\begin{array}{l}\text { Female/ } \\
\text { paediatric }\end{array}$ & $\begin{array}{l}\text { arr 10p12.33p12.32 }(19,502,326- \\
\quad 20,471,711) \times 3\end{array}$ & $\begin{array}{l}\text { 10p12.33- } \\
\text { p12.32 }\end{array}$ & Duplication & 0.97 & N/A & Scoliosis \\
\hline 13 & Male/paediatric & arr 17q21.33 $(45,861,307-45,986,282) \times 3$ & $17 q 21.33$ & Duplication & 0.12 & N/A & Developmental delay \\
\hline 14 & Male/paediatric & arr 6q14.1 $(82,900,869-83,543,710) \times 3$ & $6 q 14.1$ & Duplication & 0.64 & N/A & $\begin{array}{l}\text { Developmental delay/regres- } \\
\text { sion, asthma, severe eczema }\end{array}$ \\
\hline 15 & Male/paediatric & arr 5q33.1 $(148,226,533-148,809,596) \times 1$ & $5 q 33.1$ & Deletion & 0.58 & N/A & Nil \\
\hline
\end{tabular}

N/A not available

were highly variable. Thus, it was not feasible to derive this condition based on a collection of clinical characteristics, and genomic analysis would be indispensable for the diagnosis. Clinically, our patient had developmental delay, hypotonia, hearing loss, delayed myelination of the brain, umbilical hernia and ear canal stenosis which were deemed to be core features of distal 18q deletion [31]. In addition, congenital cardiac anomalies were also one of clinical characteristics of $18 \mathrm{q}$ deletion that were present in up to $54 \%$ patients [31-33]. For our patient, the echocardiogram was normal. Particularly, constitutional hemizygosity of $18 \mathrm{q}$ has been reported to confer increased risk of autism. Forty-three percent of patients with $18 \mathrm{q}$ deletion were categorised to be at risk of autism and the likelihood was significantly increased when TCF4, NETO1 and FBXO15 were included in the region of hemizygosity [34]. In our patient, NETO1 and FBXO15 were included in the deletion. Nevertheless, no shared region of deletion has been identified among the autistic patients with $18 \mathrm{q}$ deletion. Hence, the genetic determinants of autism in this group of patients were yet to be elucidated.

The 16p13.11 duplications were the most frequent clinically significant CNV identified in our cohort. Four patients carried the 16p13.11 duplications and all of them shared the same breakpoints at position 15.03 to 16.20 Mb. This represented $5.9 \%$ of our ASD cohort. The main mechanism underpinning the recurrent duplications and deletions at 16p13.11 is the non-allelic homologous recombination occurring between low copy repeats. The recurrent 16p13.11 duplications have established association with autism $[35,36]$ and a wide range of neuropsychiatric disorders including schizophrenia [37], attention-deficit hyperactivity disorder [38], and intellectual disability [39]. Inheritance from unaffected or mildly affected parents has been reported for the 16p13.11 duplications, indicating incomplete penetrance $[35,36]$.
Indeed, the effect of $16 \mathrm{p} 13.11$ duplications is not without controversy as its frequency in normal population is $>1 \%$ and thus being regarded as a common CNV. These duplications have been considered to be benign or uncertain significance in certain studies [40, 41]. Nevertheless, two large surveys on case-control cohorts, with case numbers of 10,397 and 29,085 respectively, have consistently demonstrated 16p13.11 duplications predisposing to ASD and other kinds of neurodevelopmental disorders with statistically significant odd ratios [42, 43]. In the earlier study for one of the aforementioned survey, the odd ratio did not reach the statistical significance with the case number of 15,767 [44]. This illustrates that a remarkably large sample size is required to demonstrate the effect of these alleles with reduced penetrance. It has been recognised that common variations are accountable for majority of the genetic risk for ASD [45]. Seemingly, this susceptibility allele has an indisputable role in the genetic architecture of autism [43]. For interpretation in individual patients, prudent judgment should be exercised for the evaluation of the CNV with reduced penetrance and complete interpretation should be made in the context of phenotypic evaluation and establishing inheritance pattern.

Interestingly, the detection rate of $16 \mathrm{p} 13.11$ duplications was relatively high in this study comparing to other $\mathrm{CNV}$ studies of ASD. Although CNV data in populationmatched controls was not available in the study, the CNV map of the human genome showed that 16p13.11 duplications were not particularly prevalent in Asian comparing to the other ethnic group [23]. Furthermore, the high proportion of duplications detected might be related the clinical characteristics of the adult cohort which they had severe impairment related to autistic symptoms but normal intelligence. It has been reported that duplications correlated to autism severity while deletions had impact on nonverbal IQ [46]. This might explain why of 
duplications were dominated in the adult cohort of this study. In addition, due to the uncertainty of the effect of 16 p13.11 duplications, the possibility of underreporting of this $\mathrm{CNV}$ in other autism studies could not be excluded.

One patient had a deletion at chromosome 14q22.1 involving the NIN gene. Compound heterozygous mutations of NIN gene were reported in microcephalic primordial dwarfism disorder [47]. We sequenced all the coding exons and flanking regions of NIN gene but did not reveal any other pathogenic mutations (data not shown). Clinically, the patient had normal growth and no dysmorphic features. NIN gene encoded for ninein, a centrosomal protein involved in microtubule anchoring. In the absence of ninein, the progenitors were prematurely depleted at the ventricular zone of the developing mammalian neocortex [48]. Having played a crucial role on microtubule stability, ninein had significant impact on the axonal development and bifurcation [49]. Disruptions of neocortex development and axon guidance were proven to be pivotal in the pathophysiology of ASD [50-53]. Those findings on the function of ninein in brain development indicated the possible link between NIN gene and autism. As exemplified by CNTNAP2 and NRXN1 gene, heterozygous missense variants confer susceptibility to autism $[54,55]$ while compound heterozygous mutations of CNTNAP2 and NRXN1 cause Pitts-Hopkins like syndrome [56]. Moreover, deletion in this region has not been reported in any normal subjects from the DGV database. Therefore, we classified this deletion as clinically significant and NIN gene might be considered to be a potential candidate gene for ASD.

This study demonstrated the spectrum of CNV in Chinese ASD patients from Hong Kong and they showed differences in certain aspects comparing with the CNV data from other studies which were mainly from European ancestry $[5,12,40,46]$. Similar to the other studies, the $\mathrm{CNV}$ detected were majority on the hotspots with recurrent breakpoints but the proportion was higher in this study. The CNV in hotspot with recurrent breakpoints generally accounted for $37-53 \%$ of CNV detected in the ASD patients in previous studies $[12,40]$ and the proportion was $62.5 \%$ (5 out of 8 clinically significant CNV) in this cohort. Moreover, CNV in 16p11.2 was demonstrated to be the most commonly detected CNV in ASD patients but it was still found in largely below $1 \%$ of ASD subjects [12, 27, 40, 46]. In contrast, the most frequently detected CNV in this cohort was 16p13.11 duplications, which were present in $5.9 \%$ of ASD patients. The reason underpinning such a high detection rate has not yet been fully elucidated but this should be validated in a larger Chinese cohort and compared with controls from the local population. The yield of highly penetrant CNV was also relatively low in this study. This could be related to the clinical characteristics of this cohort. From the review of medical record, most of the patients did not have additional clinical features apart from autism. The presence of other physical anomalies has been shown to result in higher diagnostic yield [12]. Furthermore, there was $\mathrm{CNV}$ disrupting genes that had not yet described to be linked to ASD. This concurred with other evidence showing numerous genes associated with ASD scattered across the genome and many of ASD risk genes remained to be identified.

In this study, VOUS accounted for $46.7 \%$ of all $\mathrm{CNV}$ detected (7 out of $15 \mathrm{CNV}$ ). All VOUS were less than $1 \mathrm{Mb}$ in size and majority of them were duplications. Parental results might facilitate the interpretation of the VOUS but the parental samples were not available during the recruitment which represented a limitation of this study. Yet, inheritance from parents would not completely diminish the clinical significance of variants with incomplete penetrance, like the $16 \mathrm{p} 13.11$ duplications. In addition, the small size of the duplications would not entirely preclude pathogenic effects. Indeed, evidence for dosage pathogenicity of genes in those regions would be a more important factor to be considered. To exemplify, duplication of a single gene could result in severe phenotype like in $M E C P 2$ duplication syndrome which was associated with autism and mental retardation [57]. Therefore, these VOUS might still deserve further investigations for any possible association with ASD.

It was acknowledged that limitation existed in this study. In terms of number of patients, it was relatively small in this cohort. The retrospective cohort study design also made it prone to selection bias. Moreover, this retrospective cohort of patients with confirmed diagnosis of ASD did not have systematic phenotypic documentation in details. Thus, this restricted the establishment of genotype and phenotype correlation and stratification of the diagnostic yield in patients according to additional clinical features. Another deficiency of this study is the absence of parental samples which could be helpful for the determination of the inheritance to aid the interpretation particularly for VOUS. In addition, control $\mathrm{CNV}$ data from normal individuals in the same population were lacking in the present study. The findings from this study should be validated in a larger Chinese ASD cohort from Hong Kong with $\mathrm{CNV}$ data from population-matched controls for interpretation. On the analytical aspect, the CNV findings were not checked with a second method. However, all the raw data of each CNV was manually inspected and passed the recommended quality parameters. 


\section{Conclusions}

Our study demonstrated a satisfactory diagnostic yield of array CGH in a Chinese ASD patient cohort. Having high resolution for $\mathrm{CNV}$ detection, array $\mathrm{CGH}$ made a sizeable difference to delineate the genomic alterations in ASD patients. Seemingly, the results supported the clinical usefulness of array CGH as the first tier test of ASD in Hong Kong.

\section{Additional file}

Additional file 1. Figures of array CGH data.

\section{Abbreviations \\ CGH: comparative genomic hybridization; ASD: autism spectrum disorder; CMA: chromosomal microarray; CNV: copy number variants; VOUS: variants of uncertain significance.}

\section{Authors' contributions}

WKS recruited the participants, performed the array $\mathrm{CGH}$, analysed the data and drafted the manuscript. CWL wrote the protocol, performed data interpretation and reviewed the manuscript. CMM wrote the protocol and reviewed the manuscript. ETKL, MHYT, WFT performed the array CGH and reviewed the data. RSMPM, CCL, SFH, PWLL, KLL, EKCY, GSFN, KYC recruited the participants and delineated the clinical diagnosis. NCF performed reverse phenotyping for Patient 7. All authors read and approved the final manuscript.

\section{Author details}

'Department of Pathology, The University of Hong Kong, 102 Pokfulam Road, Hong Kong, China. ${ }^{2}$ Kowloon West Cluster Laboratory Genetics Service, Department of Pathology, Princess Margaret Hospital, Hong Kong, China. ${ }^{3}$ Department of Obstetrics and Gynaecology, The University of Hong Kong, Queen Mary Hospital, Hong Kong, China. ${ }^{4}$ Department of Clinical Psychology, Kwai Chung Hospital, Hong Kong, China. ${ }^{5}$ Department of Psychiatry, Kwai Chung Hospital, Hong Kong, China. ${ }^{6}$ Department of Psychology, The Chinese University of Hong Kong, Hong Kong, China. ${ }^{7}$ Department of Paediatrics and Adolescent Medicine, Tuen Mun Hospital, Hong Kong, China. ${ }^{8}$ Department of Paediatrics and Adolescent Medicine, Princess Margaret Hospital, Hong Kong, China.

\section{Acknowledgements}

This work was supported by Chan Woon Cheung Education and Research Fund in Pathology of The Hong Kong College of Pathologists.

\section{Competing interests}

The authors declare that they have no competing interests.

Received: 1 December 2015 Accepted: 4 May 2016

Published online: 16 May 2016

\section{References}

1. Elsabbagh M, Divan G, Koh YJ, Kim YS, Kauchali S, Marcin C et al (2012) Global prevalence of autism and other pervasive developmental disorders. Autism Res 5(3):160-179. doi:10.1002/aur.239

2. Chang J, Gilman SR, Chiang AH, Sanders SJ, Vitkup D (2015) Genotype to phenotype relationships in autism spectrum disorders. Nat Neurosci 18(2):191-198. doi:10.1038/nn.3907

3. Vorstman JA, Staal WG, van Daalen E, van Engeland H, Hochstenbach PF, Franke $L$ (2006) Identification of novel autism candidate regions through analysis of reported cytogenetic abnormalities associated with autism. Mol Psychiatry 11(1):18-28. doi:10.1038/sj.mp.4001757

4. Reddy KS (2005) Cytogenetic abnormalities and fragile-X syndrome in autism spectrum disorder. BMC Med Genet 6:3. doi:10.1186/1471-2350-6-3
5. Pinto D, Pagnamenta AT, Klei L, Anney R, Merico D, Regan R et al (2010) Functional impact of global rare copy number variation in autism spectrum disorders. Nature 466(7304):368-372. doi:10.1038/nature09146

6. Miller DT, Adam MP, Aradhya S, Biesecker LG, Brothman AR, Carter NP et al (2010) Consensus statement: chromosomal microarray is a first-tier clinical diagnostic test for individuals with developmental disabilities or congenital anomalies. Am J Hum Genet 86(5):749-764. doi:10.1016/j. ajhg.2010.04.006

7. Roberts JL, Hovanes K, Dasouki M, Manzardo AM, Butler MG (2014) Chromosomal microarray analysis of consecutive individuals with autism spectrum disorders or learning disability presenting for genetic services. Gene 535(1):70-78. doi:10.1016/j.gene.2013.10.020

8. Nicholl J, Waters W, Mulley JC, Suwalski S, Brown S, Hull Y et al (2014) Cognitive deficit and autism spectrum disorders: prospective diagnosis by array CGH. Pathology 46(1):41-45. doi:10.1097/PAT.0000000000000043

9. Battaglia A, Doccini V, Bernardini L, Novelli A, Loddo S, Capalbo A et al (2013) Confirmation of chromosomal microarray as a first-tier clinical diagnostic test for individuals with developmental delay, intellectual disability, autism spectrum disorders and dysmorphic features. Eur J Paediatr Neurol 17(6):589-599. doi:10.1016/j.ejpn.2013.04.010

10. McGrew SG, Peters BR, Crittendon JA, Veenstra-Vanderweele J (2012) Diagnostic yield of chromosomal microarray analysis in an autism primary care practice: which guidelines to implement? J Autism Dev Disord 42(8):1582-1591. doi:10.1007/s10803-011-1398-3

11. Shen Y, Dies KA, Holm IA, Bridgemohan C, Sobeih MM, Caronna EB et al (2010) Clinical genetic testing for patients with autism spectrum disorders. Pediatrics 125(4):e727-e735. doi:10.1542/peds.2009-1684

12. Tammimies K, Marshall CR, Walker S, Kaur G, Thiruvahindrapuram B, Lione AC et al (2015) Molecular diagnostic yield of chromosomal microarray analysis and whole-exome sequencing in children with autism spectrum disorder. JAMA 314(9):895-903. doi:10.1001/jama.2015.10078

13. Poon Mak SM (2009) Adult Outcome of Children with autism with normal intelligence Hong Kong: The Chinese University of Hong Kong

14. Lai KY, Leung PW, Mo FY, Lee MM, Shea CK, Chan GF et al (2015) Validation of the developmental, dimensional and diagnostic interview (3Di) among Chinese children in a child psychiatry clinic in Hong Kong. J Autism Dev Disord 45(5):1230-1237. doi:10.1007/s10803-014-2284-6

15. Wechsler D (2002) Wechsler adult intelligence scale-3rd edition (Chinese Version). Chinese Behav Sci Corp, Taiwan

16. Rutter M, Le Couteur A, Lord C (2003) Autism diagnostic interview-revised (ADI-R) manual. Western Psychological Services, Los Angeles

17. Kan AS, Lau ET, Tang WF, Chan SS, Ding SC, Chan KY et al (2014) Wholegenome array CGH evaluation for replacing prenatal karyotyping in Hong Kong. PLOS ONE 9(2):e87988. doi:10.1371/journal.pone.0087988

18. Rim JH, Kim SW, Han SH, Yoo J (2015) Clinical and molecular delineation of a novel de novo 4q28.3-31.21 interstitial deletion in a patient with developmental delay. Yonsei Med J 56(6):1742-1744. doi:10.3349/ ymj.2015.56.6.1742

19. Kim J, Won HH, Kim Y, Choi JR, Yu N, Lee KA (2015) Breakpoint mapping by whole genome sequencing identifies PTH2R gene disruption in a patient with midline craniosynostosis and a de novo balanced chromosomal rearrangement. J Med Genet 52(10):706-709. doi:10.1136/ jmedgenet-2015-103001

20. Genesio R, Fontana P, Mormile A, Casertano A, Falco M, Conti A et al (2015) Constitutional chromothripsis involving the critical region of 9q21.13 microdeletion syndrome. Mol Cytogenet 8:96. doi:10.1186/ s13039-015-0199-3

21. Beke A, Piko H, Haltrich I, Csomor J, Matolcsy A, Fekete G et al (2013) Molecular cytogenetic analysis of $\mathrm{Xq}$ critical regions in premature ovarian failure. Mol Cytogenet 6(1):62. doi:10.1186/1755-8166-6-62

22. Kearney HM, Thorland EC, Brown KK, Quintero-Rivera F, South ST (2011) Working group of the american college of medical genetics laboratory quality assurance C. American College of Medical Genetics standards and guidelines for interpretation and reporting of postnatal constitutional copy number variants. Genetics in medicine: official journal of the American College of Medical. Genetics 13(7):680-685. doi:10.1097/ GIM.0b013e3182217a3a

23. Zarrei M, MacDonald JR, Merico D, Scherer SW (2015) A copy number variation map of the human genome. Nat Rev Genet 16(3):172-183. doi:10.1038/nrg3871 
24. Sebat J, Lakshmi B, Malhotra D, Troge J, Lese-Martin C, Walsh T et al (2007) Strong association of de novo copy number mutations with autism. Science 316(5823):445-449. doi:10.1126/science.1138659

25. Burnside RD, Pasion R, Mikhail FM, Carroll AJ, Robin NH, Youngs EL et al (2011) Microdeletion/microduplication of proximal 15q11.2 between BP1 and BP2: a susceptibility region for neurological dysfunction including developmental and language delay. Hum Genet 130(4):517-528. doi:10.1007/s00439-011-0970-4

26. Doornbos M, Sikkema-Raddatz B, Ruijvenkamp CA, Dijkhuizen T, Bijlsma EK, Gijsbers AC et al (2009) Nine patients with a microdeletion 15q11.2 between breakpoints 1 and 2 of the Prader-Willi critical region, possibly associated with behavioural disturbances. Eur J Med Genet 52(2-3):108115. doi:10.1016/j.ejmg.2009.03.010

27. Marshall CR, Noor A, Vincent JB, Lionel AC, Feuk L, Skaug J et al (2008) Structural variation of chromosomes in autism spectrum disorder. Am Hum Genet 82(2):477-488. doi:10.1016/j.ajhg.2007.12.009

28. Mclnnes LA, Nakamine A, Pilorge M, Brandt T, Jimenez Gonzalez P, Fallas $M$ et al (2010) A large-scale survey of the novel 15q24 microdeletion syndrome in autism spectrum disorders identifies an atypical deletion that narrows the critical region. Mol Autism 1(1):5. doi:10.1186/2040-2392-1-5

29. Siu WK, Lam CW, Gao WW, Tang VH, Jin DY, Mak CM (2015) Unmasking a novel disease gene NEO1 associated with autism spectrum disorders by a hemizygous deletion on chromosome 15 and a functional polymorphism. Behav Brain Res. doi:10.1016/j.bbr.2015.10.041

30. Heard PL, Carter EM, Crandall AC, Sebold C, Hale DE, Cody JD (2009) High resolution genomic analysis of $18 \mathrm{q}$ - using oligo-microarray comparative genomic hybridization (aCGH). Am J Med Genet A 149A(7):1431-1437. doi:10.1002/ajmg.a.32900

31. Cody JD, Hasi M, Soileau B, Heard P, Carter E, Sebold C et al (2014) Establishing a reference group for distal 18q-: clinical description and molecular basis. Hum Genet 133(2):199-209. doi:10.1007/s00439-013-1364-6

32. Versacci P, Digilio MC, Sauer U, Dallapiccola B, Marino B (2005) Absent pulmonary valve with intact ventricular septum and patent ductus arteriosus: a specific cardiac phenotype associated with deletion $18 \mathrm{q}$ syndrome. Am J Med Genet A 138A(2):185-186. doi:10.1002/ajmg.a.30916

33. van Trier DC, Feenstra I, Bot P, de Leeuw N, Draaisma JM (2013) CardiaC anomalies in individuals with the $18 \mathrm{q}$ deletion syndrome; report of a child with Ebstein anomaly and review of the literature. Eur J Med Genet 56(8):426-431. doi:10.1016/j.ejmg.2013.05.002

34. O'Donnell L, Soileau B, Heard P, Carter E, Sebold C, Gelfond J et al (2010) Genetic determinants of autism in individuals with deletions of 18q. Hum Genet 128(2):155-164. doi:10.1007/s00439-010-0839-y

35. Ullmann R, Turner G, Kirchhoff M, Chen W, Tonge B, Rosenberg C et al (2007) Array CGH identifies reciprocal 16p13.1 duplications and deletions that predispose to autism and/or mental retardation. Hum Mutat 28(7):674-682. doi:10.1002/humu.20546

36. Ramalingam A, Zhou XG, Fiedler SD, Brawner SJ, Joyce JM, Liu HY et al (2011) 16p13.11 duplication is a risk factor for a wide spectrum of neuropsychiatric disorders. J Hum Genet 56(7):541-544. doi:10.1038/ jhg.2011.42

37. Ingason A, Rujescu D, Cichon S, Sigurdsson E, Sigmundsson T, Pietilainen OP et al (2011) Copy number variations of chromosome 16p13.1 region associated with schizophrenia. Mol Psychiatry 16(1):17-25. doi:10.1038/ mp.2009.101

38. Williams NM, Zaharieva I, Martin A, Langley K, Mantripragada K, Fossdal R et al (2010) Rare chromosomal deletions and duplications in attention-deficit hyperactivity disorder: a genome-wide analysis. Lancet 376(9750):1401-1408. doi:10.1016/S0140-6736(10)61109-9

39. Mefford HC, Cooper GM, Zerr T, Smith JD, Baker C, Shafer N et al (2009) A method for rapid, targeted CNV genotyping identifies rare variants associated with neurocognitive disease. Genome Res 19(9):1579-1585. doi:10.1101/gr.094987.109

40. Pinto D, Delaby E, Merico D, Barbosa M, Merikangas A, Klei L et al (2014) Convergence of genes and cellular pathways dysregulated in autism spectrum disorders. Am J Hum Genet 94(5):677-694. doi:10.1016/j. ajhg.2014.03.018

41. Hannes FD, Sharp AJ, Mefford HC, de Ravel T, Ruivenkamp CA, Breuning $\mathrm{MH}$ et al (2009) Recurrent reciprocal deletions and duplications of 16p13.11: the deletion is a risk factor for MR/MCA while the duplication may be a rare benign variant. J Med Genet 46(4):223-232. doi:10.1136/ jmg.2007.055202

42. Tropeano M, Ahn JW, Dobson RJ, Breen G, Rucker J, Dixit A et al (2013) Male-biased autosomal effect of 16p13.11 copy number variation in neurodevelopmental disorders. PLoS ONE 8(4):e61365. doi:10.1371/journal. pone.0061365

43. Coe BP, Witherspoon K, Rosenfeld JA, van Bon BW, Vulto-van Silfhout AT, Bosco P et al (2014) Refining analyses of copy number variation identifies specific genes associated with developmental delay. Nat Genet 46(10):1063-1071. doi:10.1038/ng.3092

44. Cooper GM, Coe BP, Girirajan S, Rosenfeld JA, Vu TH, Baker C et al (2011) A copy number variation morbidity map of developmental delay. Nat Genet 43(9):838-846. doi:10.1038/ng.909

45. Gaugler T, Klei L, Sanders SJ, Bodea CA, Goldberg AP, Lee AB et al (2014) Most genetic risk for autism resides with common variation. Nat Genet 46(8):881-885. doi:10.1038/ng.3039

46. Girirajan S, Dennis MY, Baker C, Malig M, Coe BP, Campbell CD et al (2013) Refinement and discovery of new hotspots of copy-number variation associated with autism spectrum disorder. Am J Hum Genet 92(2):221237. doi:10.1016/j.ajhg.2012.12.016

47. Dauber A, Lafranchi SH, Maliga Z, Lui JC, Moon JE, McDeed C et al (2012) Novel microcephalic primordial dwarfism disorder associated with variants in the centrosomal protein ninein. J Clin Endocrinol Metab 97(11):E2140-E2151. doi:10.1210/jc.2012-2150

48. Wang X, Tsai JW, Imai JH, Lian WN, Vallee RB, Shi SH (2009) Asymmetric centrosome inheritance maintains neural progenitors in the neocortex. Nature 461(7266):947-955. doi:10.1038/nature08435

49. Srivatsa S, Parthasarathy S, Molnar Z, Tarabykin V (2015) Sip 1 downstream Effector ninein controls neocortical axonal growth, ipsilateral branching, and microtubule growth and stability. Neuron 85(5):998-1012. doi:10.1016/j.neuron.2015.01.018

50. Blockus H, Chedotal A (2014) The multifaceted roles of Slits and Robos in cortical circuits: from proliferation to axon guidance and neurological diseases. Curr Opin Neurobiol 27C:82-88. doi:10.1016/j.conb.2014.03.003

51. Chu J, Anderson SA (2015) Development of cortical interneurons. Neuropsychopharmacology 40(1):16-23. doi:10.1038/npp.2014.171

52. Marin O (2012) Interneuron dysfunction in psychiatric disorders. Nat Rev Neurosci 13(2):107-120. doi:10.1038/nrn3155

53. Robichaux MA, Cowan CW (2014) Signaling mechanisms of axon guidance and early synaptogenesis. Curr Top Behavl Neurosci 16:19-48. doi:10.1007/7854_2013_255

54. Alarcon M, Abrahams BS, Stone JL, Duvall JA, Perederiy JV, Bomar JM et al (2008) Linkage, association, and gene-expression analyses identify CNTNAP2 as an autism-susceptibility gene. Am J Hum Genet 82(1):150-159. doi:10.1016/j.ajhg.2007.09.005

55. Penagarikano O, Abrahams BS, Herman El, Winden KD, Gdalyahu A, Dong $\mathrm{H}$ et al (2011) Absence of CNTNAP2 leads to epilepsy, neuronal migration abnormalities, and core autism-related deficits. Cell 147(1):235-246. doi:10.1016/j.cell.2011.08.040

56. Zweier C, de Jong EK, Zweier M, Orrico A, Ousager LB, Collins AL et al (2009) CNTNAP2 and NRXN1 are mutated in autosomal-recessive Pitt-Hopkins-like mental retardation and determine the level of a common synaptic protein in Drosophila. Am J Hum Genet 85(5):655-666. doi:10.1016/j.ajhg.2009.10.004

57. Ramocki MB, Tavyev YJ, Peters SU (2010) The MECP2 duplication syndrome. Am J Med Genet A 152A(5):1079-1088. doi:10.1002/ajmg.a.33184 